\title{
Paleofire knowledge for current and future ecosystem management
}

\author{
Olivier Blarquez', P. Grondin ${ }^{2}$ and the GPWG2
}

Montreal, Canada, 10-14 October 2017

In the past year, fires raged in different places around the world and their impacts on human lives, livelihoods and infrastructures were unprecedented. The long-antic ipated effects of ongoing global changes on fire dynamics are now a reality, and have consequences on the functioning of ecosystems themselves, including, among others, loss of resilience, exceeding known range of fire regime variability and burning of ecosys tems for which fire was supposedly absent. For example, the length of the California (USA) fire season in 2017 almost doubled, with fires blazing as late as December, and large fires developed in the Greenland tundra where they are unprecedented. Those unusual events modified the global carbon cycle and aerosol emissions, threatened human lives and infrastructures and, associated with climate change, may decrease ecosystem resilience (Stevens-Rumann et al. 2017). In this context, researchers, landscape managers and decision-makers from across the planet are being challenged to reintegrate natural disturbance processes into ecosystem management plans.

PAGES' Global Paleofire Working Group 2 (GPWG2) organized a workshop which aimed to gather paleofire experts and stakeholders, including governmental agencies, in order to assess the use of long-term fire history for future fire and ecosystem management. Twenty-three participants from 10 countries at all career stages presented their research and worked together on strengthening the links between management and paleofire research.

Before the workshop, each participant was asked to contact a stakeholder, manager or decision-maker from their country of origin to survey their knowledge and interest in paleofire research using a questionnaire that was prepared by the workshop organizers. Several challenges in engaging stakeholders and interesting them in paleofire research emerged from the questionnaire answers and were discussed. Although the use of paleofire records for future ecosystem management has been the topic of several recent studies (e.g. Gillson and Marchant 2014; Girardin et al. 2013), paleofire knowledge is rarely translated into effective management tools and tends to remain a purely theoretical discipline.

Better communication between paleoecologists and managers thus appeared to be the first goal to achieve - but several challenges remain, such as avoiding the use of jargon

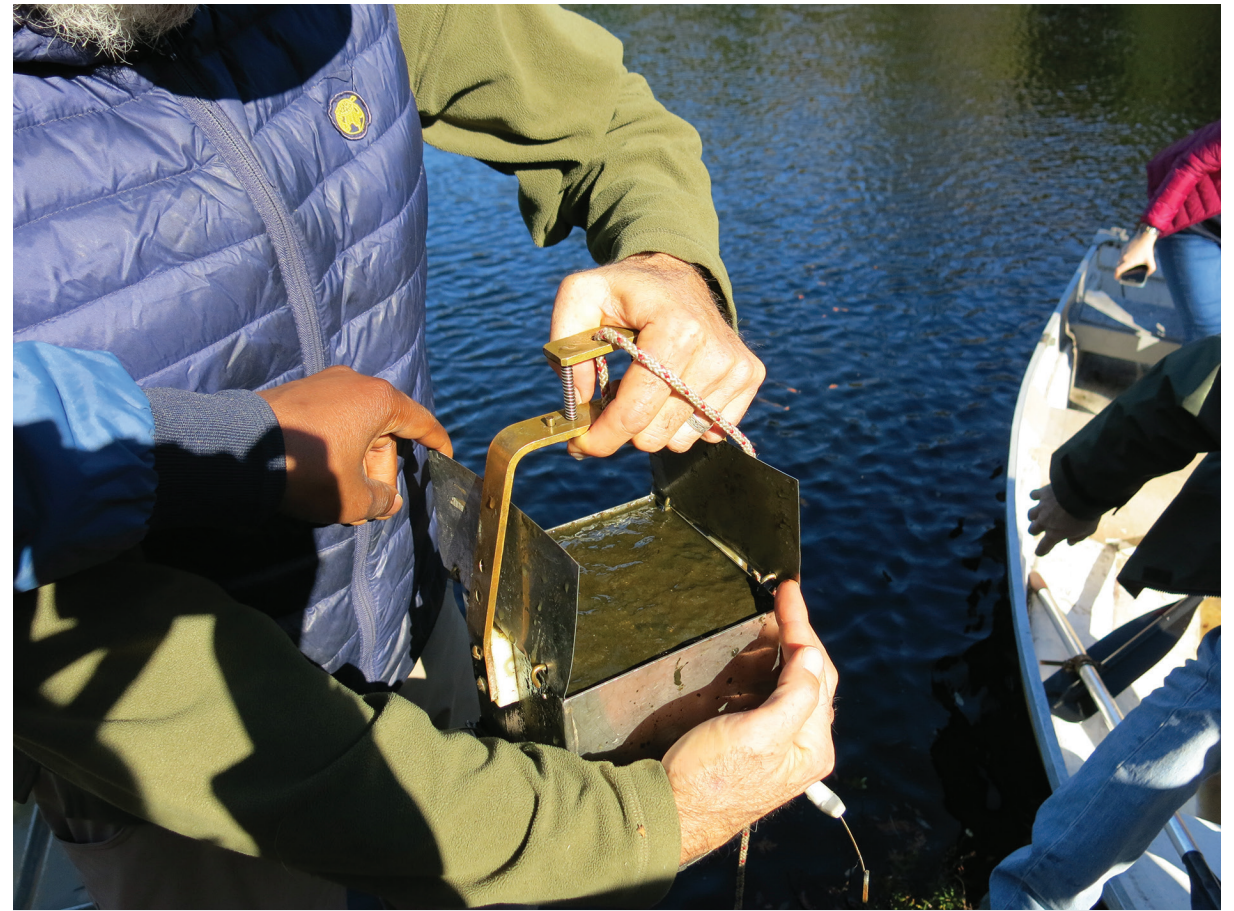

Figure 1: Lac Geai (Canada) surface sediment sampling with an Eckman sampler used to take the first sample for the Global Modern Charcoal Dataset (GMCD) initiative (Hawthorne et al., in press). Image credit: Katarzyna Marcisz.

and using a common vocabulary. These points crucially require the calibration of paleoecological data that could translate past ecological processes into more measurable units (Hawthorne et al., in press). Currently the Global Charcoal Database (GCD, http:// paleofire.org) and associated R paleofire package (Blarquez et al. 2014) only gather information on raw charcoal data, which are not directly useful to stakeholders. The development of new products associated with the GCD, such as a database of fire return intervals or other fire regime metrics calculated upon raw GCD data, has the potential to increase paleofire data use for management and will enhance the visibility of the discipline.

While necessary, this is, however, probably not sufficient and the questionnaire highlighted the need for strengthening partnerships between stakeholders and scientists. Co-design of research is starting to emerge in the geoscience field (Vano et al. 2017) and should contribute to make science more useful for communities and future ecosystem management. Several outcomes and products of the Montreal workshop will help paleofire science to follow that trend. There will be (i) the edition of a glossary that will merge terminologies used in paleofire science, ecosystem management and decision-making, and (ii) an updated questionnaire, which will be shared more broadly, to enable scientists to more effectively communicate with local actors and start new partnerships. The development of new methodological tools, such as improved calibration and interpreted past fire metrics from the GCD, will permit (iii) a better communication of paleofire knowledge via open source tools and data (See http://paleofire.org for details).

\section{AFFILIATIONS}

'Department of Geography, University of Montréal, Canada

${ }^{2}$ Ministère des Forêts, de la Faune et des Parcs du Québec, Québec City, Canada

\section{CONTACT}

Olivier Blarquez: olivier.blarquez@umontreal.ca REFERENCES

Blarquez O et al. (2014) Comput Geosci 72: 255-261 Gillson L, Marchant R (2014) Trends Ecol Evol 29: 317-325 Girardin MP et al. (2013) For Ecol Manag 294: 238-249

Hawthorne D et al. (in press) Quat Int

Stevens-Rumann CS et al. (2017) Ecol Lett 21: 243-252

Vano JA et al. (2017) Eos 98 